\title{
Taxation and growth: Why does it matter and how can it be analysed?
}

\author{
SALVADOR BARRIOS*
}

Joint Research Centre, European Commission, Ispra, Italy

Received: October 27, 2019 • Revised manuscript received: July 01, 2020 • Accepted: July 02, 2020

Published online: September 02, 2020

(C) 2020 The Author(s)

\begin{abstract}
The growth impact of tax reforms is probably one of the most controversial issues in economic policy discussions, reflecting deep beliefs in the way economic agents are expected to react to policy changes. The optimal tax theory literature provides a wide array of arguments to identify the mechanisms through which tax reforms might influence growth, depending on the tax category considered and the circumstances under which tax reforms are implemented. The empirical literature has relied on the use of cross-country growth regressions and provided general results leading to normative conclusions on the desirability of specific tax reform options. However, recent research has shown that this approach yields inconclusive results, notably due to identification and endogeneity issues, and the difficulty to account for the true determinants of governments' actions. The dynamic scoring approach combining microsimulation and macro models proves more useful in this respect, especially in order to draw policy recommendations while accounting for the second-round effects of tax reforms. I illustrate these arguments by analysing the growth impact of a hypothetical change from the current flat personal income tax (PIT) rates to progressive taxes in Central and Eastern European (CEE) countries. I find that the estimated impact of such a reform would be rather small but positive when using the dynamic scoring method, while the less-reliable traditional growth regressions would suggest adverse growth effects.
\end{abstract}

\section{KEYWORDS}

taxation, growth, fiscal policy, dynamic scoring, econometric estimations

\section{JEL-CODES}

E62, H21, H22, 047

\footnotetext{
*Corresponding author. E-mail: Salvador.BARRIOS@ec.europa.eu
} 
"We unleashed and economic miracle by signing the biggest tax cuts in American history."

Donald Trump, www.whithouse.gov, June 29, 2018.

"We will respond to the economic and social urgency with strong measures by cutting taxes more rapidly..."

Emmanuel Macron, CNBC, December 10, 2018.

"We are convinced that if you lower taxes, the state receives less in the first year but from the second it receives more, the money is spent and invested."

Matteo Salvini, Bloomberg, March 18, 2019.

\section{INTRODUCTION}

As the quotes above illustrate, tax reform proposals are often given the "growth-friendly" label by their supporters. Recently, the growth argument has been coupled with concerns for social justice, given the mounting evidence on growing income disparities in the aftermath of the global financial crisis and the Great Lockdown. The growth impact of tax reforms represents one of the main dividing lines in public discussions and political debates. This divide reflects differences in assumptions regarding the way economic agents (i.e. businesses or individuals) would eventually react to tax reforms. For instance, some politicians would argue that corporate tax cuts are the best way to boost investment and ultimately lead to higher tax revenues in the future. Others would believe instead that investment primarily depends on employment and consumption, and that corporate tax cuts are both costly and ineffective. Views also differ on the way individuals would react to a labour tax reduction, which could lead to an increase in labour supply and employment creation, or rather have little impact on employment and are likely to be captured by firms through wage reduction.

Assumptions regarding behavioural reactions play a key role in promoting specific tax reforms against others and drawing inferences on their growth impact. The economic literature provides a wide array of arguments on the magnitude and direction of behavioural reactions, sometimes going in opposite directions as illustrated above. This variety of results in turn echoes in public debates. While this makes political debates entertaining, it is less of a good thing for the policy analysist whose aim is to provide an objective assessment of alternative policy options.

This paper briefly reviews the main theoretical arguments underlying the analysis of the growth impact of tax reforms. I then discuss the way such analysis can be conducted, by comparing two different approaches: a traditional empirical growth analysis based on crosscountry econometric estimations and a dynamic scoring approach combining microsimulation modelling with a macroeconomic model. I do not discuss other approaches such as the structural VAR approach (Blanchard - Perotti 2002) or the narrative approach (Romer - Romer 2010), see Dabla-Norris and Lima (2018) and Van der Wielen (2020) for recent applications of these. These alternative methods have addressed identification issues and proposed a reduced form approach providing a useful guide for policy practitioners for optimal policy decision over the short to medium term. However, my discussion focuses on the structural features of the economy and the impact of tax policy decisions on long-run growth. 
The choice of comparing empirical growth equations with an alternative approach is not accidental. As a matter of fact, the empirical literature on taxation and growth provides general results which, when taken at face value, can lead to biased policy conclusions. In this context, I argue that a dynamic scoring approach, combining theoretical and microsimulation models, provides a reliable tool for assessing the growth impact of tax reforms as it suffers less from methodological issues and allows for a proper identification of the impact of policy change, by contrast with results based on growth regression analyses. I discuss these questions and illustrate the use of these two approaches by analysing the impact of hypothetical progressive personal income tax (PIT) reforms in those Central and Eastern European (CEE) countries that currently apply a flat tax system. Section 2 provides an overview of arguments developed in the theoretical and empirical literature on tax policy and economic growth. Section 3 summarises the dynamic scoring approach. Section 4 illustrates these arguments by considering the case of PIT reforms in CEE countries and comparing the simulations obtained from a standard growth equation with a dynamic scoring approach. My findings and interpretation are summarised in a concluding section.

\section{TAX POLICY AND GROWTH: A BRIEF REVIEW OF THE LITERATURE}

What does economic theory say about the expected impact of tax reforms on long-run growth? Are empirical results robust enough in order to validate the theory? In this section, I briefly review the main elements usually considered in the academic literature on the growth impact of taxation. I consider in particular the case of labour, capital, human capital and R\&D, the latter two elements being the main determinants of productivity, which is ultimately the main driver of long-run growth. I will also provide a more extensive discussion on labour taxes, given that this is the focus on the empirical example presented in this paper.

As suggested previously, the key aspect of tax reforms concerns the way they distort decisions taken by economic agents. The size of these distortions is represented by the so-called deadweight loss of taxation, which represents an efficiency losses, see in particular Auerbach and Hines (2002). Let us consider the case of labour taxes and employment for instance. The theory tells us that the deadweight loss of labour taxes is proportional to the elasticity of labour supply with respect to net wages (Feldstein 2006). A general formula for deriving optimal tax rates was proposed by Saez (2001), who showed how compensated and uncompensated elasticities of earnings with respect to tax rates could be used to derive optimal tax rates for high income. Diamond and Saez (2011) similarly build on differences in reactivity to tax reforms across the income distribution to advocate for progressive tax reforms, including high and rising marginal tax rates on high income coupled with capital income taxation. For low and medium income individuals, a similar reasoning can be followed, although in this case elasticities of earnings are intrinsically linked to elasticities of labour supply at the extensive margin (i.e. concerning the decision to work or not), given that labour income is usually their main source of revenue. The empirical evidence suggests that labour supply elasticities are usually higher for certain types of individuals (e.g. married women, single parents), especially in the presence of generous social benefits leading to very high marginal tax rates (Blundell 2012). This leads Diamond and Saez (2011) to argue that low income earners should be subsidized through working tax credit in order to reduce the potential disincentive effects of introducing progressivity in tax systems. 
Recent empirical evidence tends to support this view, suggesting in particular that progressive tax reforms can be designed in order to yield greater equity and improved incentives for lowincome earners resulting in net economic and fiscal gains (Gerber et al. 2018).

These questions are in fact a bit more intricate when considering the taxation of high income earners, given the need to consider also capital (and savings) taxation in addition to labour taxation. In this case, the behavioural effects also include the mobility of capital across constituencies (countries, regions, etc.) and across tax bases through tax shifting from labour to capital or through different forms of capital holding, be it through financial intermediaries or shareholding. These behavioural effects represent additional tax avoidance schemes for high income categories and can lead to large efficiency losses (Auerbach et al. 2010). Therefore, the important question regarding capital taxation becomes the proper definition of the tax base, which unlike labour, can take multiple forms, and has a key inter-temporal dimension, resulting in potentially large distortionary effects on long-run investment and growth.

The literature on capital taxation provides a broad set of policy recommendations for tax policy reforms, running from zero (see the earlier analyses of Atkinson and Stiglitz 1976; Judd 1985; and Chamley 1986) to positive, and sometimes very high tax rates, as in the case of wealth taxation, see in particular Piketty and Saez (2012), Aghion et al. (2013) and Bastani and Waldenström (2018) for a recent review of the literature. The literature has more recently dealt with the taxation of broader types of capital, such as R\&D and human capital, highlighting the complexity of striking an optimal balance between labour and capital taxation. Akcigit et al. (2019) in particular show that both tax types matter for innovation and long-run growth.

The empirical literature provides even less clear-cut results on the possible causality between taxation and growth. The influential paper by Arnold et al. (2011) used cross-country panel econometric regressions and suggested that tax categories could be ranked according to their impact on growth. According to these authors, property and consumption taxes would be the least detrimental taxes while personal and capital income taxes would be the most harmful ones. This work was recently updated by Akgun et al. (2017) who confirmed the previous authors' findings, according to which cuts in corporate income taxes, reduction in labour tax wedges and increases in property taxes tend to lift growth in the long-run.

These results have recently been questioned, mainly due to their lack of robustness and their sensitivity to the econometric method used, see in particular Xing (2012) and Baiardi et al. (2019). These limitations are not surprising given that taxation is only one dimension of growth and is unlikely to be the most important one. Institutions and rule of law, human capital, capital accumulation, international trade, and demographic factors, to name a few, are generally considered as being the main determinants of long-run growth. For instance, the seminal paper by Easterly and Rebelo (1993) does not find a strong effect of taxation on growth, while demographic dynamics appeared as the main conditioning factor. These authors highlight nevertheless the relation between the development level and fiscal structures, with low-income countries relying more on international trade taxes rather than income taxes. Similarly, influential paper by Stokey and Rebelo (1995) concludes that the tax system is relatively neutral with respect to growth and that changes in tax rates cannot have large effects.

One could argue that, since taxes are used to finance public services and public investment, they could affect economic growth, at least indirectly. However, this influence is likely to be only marginal and diluted through the economic system. The latter is evidenced by the analysis of tax incidence, whereby the legal incidence of taxes might differ, sometimes significantly, from their 
true economic incidence (Fullerton - Metcalf 2002). For instance, a labour tax hike may hinder job creation, although to a different extent depending on job skills. For certain types of workers, companies may decide to absorb part of the tax increase by cutting on profits in order to keep wage levels unchanged and to retain high skilled workers (Bingley - Lanot 2002). Similarly, corporate tax increases might result in lower wages for low skilled workers (Fuest et al. 2018; Suárez-Serrato - Zidar 2016), but leave corporate investment relatively unaffected (Yagan 2015). Tax reforms may thus have unintended effects depending on the tax category considered and the context under which they are carried out. The relevant point here is that the effectiveness of tax reforms is likely to depend on the distance between the legal and the economic incidence. The existing evidence suggests that the latter tends to be proportional to behavioural responses and firms' mark-ups. ${ }^{1}$

The previous discussion shows that both theoretical and empirical analyses lead to a wide array of arguments on the causal link between tax reforms and growth. Yet, this apparent inconclusiveness should not prevent us from considering the growth impact of tax reforms very carefully. The main reason for this is that tax reforms are one of the main tools for policy action, which needs to be evaluated from a growth perspective too, although not necessarily in order to draw normative conclusions, but rather as a practical tool to evaluate alternative policy options. Tax reforms should in particular be gauged in terms of their efficiency and design, by determining the extent to which they are self-financed. When addressing this question, the analysis must consider the behavioural and second-round impact of tax reforms on the economy, since tax revenues are generated through economic activity. The optimal tax theory provides us with the elements necessary to address these questions, although these elements should be put in the context of the specific policy reform being considered. Such an analysis is complex, however, and departs significantly from the one-size-fits-all approach that often motivates cross-country econometric analyses, which can lead to misinterpretations and biased policy assessment. In the following, I describe how such an approach is implemented at the European Commission, building on practice built elsewhere, in particular in the US, over the last two decades.

\section{THE USE OF DYNAMIC SCORING FOR THE ANALYSIS OF TAXATION AND GROWTH}

As discussed above, the growth impact of tax reforms represents the main point of debates surrounding tax reforms and budgetary laws. However, these discussions are not systematically grounded on independent assessment and even less so on state of the art economic analysis and modelling, with a few noticeable exceptions. For instance, the need for dependable estimates of the impact of tax reforms was enshrined into law in the US with the Joint Committee on Taxation (JCT) being officially responsible for providing macroeconomic impact assessment of changes in tax law since 2003. This assessment is in turn used by the Congressional Budgetary Office in order to provide estimates, or "scores", of the fiscal effects on these reforms. The tax revenue effects of changes in tax law therefore incorporate its second round effects on the

\footnotetext{
${ }^{1}$ See Barrios et al. (2018b) for cross-country and industry-level evidence on the role of mark-ups and behavioural responses to determine the direction and level of tax incidence.
} 
economy, including its growth impact (Gravelle 2014). Similar types of analyses are also conducted elsewhere, with the UK and the Netherlands possibly standing out as the countries with the strongest tradition in conducting similar assessment on a regular basis. In the Netherlands, the Centraal Planbureau ( $\mathrm{CPB}$ ) provides the projections used in building the government budget. Since 1986, the CPB has been analysing the programmes of political parties in general elections upon their request, providing the basis for an objective comparison of alternative policy reforms. The Office for Budget Responsibility in the UK acts as an independent fiscal watchdog focussing on the long-run sustainability of public finances and applies a similar dynamic scoring approach.

The practice of dynamic scoring remains limited and not systematically used for assessing specific tax reforms, however. The Joint Research Centre, in partnership with the Directorate General for Economic and Financial Affairs of the European Commission, have recently developed their own dynamic scoring approach, which is now used in the context of the European Semester process to analyse the impact of hypothetical or actual tax reforms in EU member states. This approach is described in more details in Barrios et al. (2019). Here I explain briefly its main features.

The European Commission approach to dynamic scoring makes use of two main models: a microsimulation model, EUROMOD and the Dynamic Stochastic General Equilibrium model QUEST, both covering all EU countries (Ratto et al. 2009; Sutherland - Figari 2013). ${ }^{2}$ The dynamic scoring follows two main steps: first, it provides a micro-level analysis of the impact of tax reforms for individuals and households (private businesses are not yet covered) and derives the parameters, most notably the changes in the implicit tax rates led by tax policy reforms, which are then incorporated into the QUEST model in order to analyse their macroeconomic consequences. Both models are connected through labour supply (in particular labour supply elasticities and non-participation rates) and prices, including grows wages and consumer price indices. Labour supply parameters are estimated using a standard labour supply model based on Bargain et al. (2014).

The dynamic scoring approach is warranted in order to analyse the impact of tax reforms on growth. First, the assumptions and hypotheses regarding behavioural effects are made transparent (and can certainly be adjusted in order to account for different views and alternative scenarios). This represents a major advantage in order to address the issue of tax incidence. The labour market plays a pivotal role in this respect. As explained above, tax reforms are first simulated in the EUROMOD microsimulation model, leading to changes in the implicit tax rates and gross wages, which then potentially influence labour supply. Yet, this is not the end of the story given that final (net) wages also depend on the tax and social benefits and the potential reaction of labour demand. The end result will depend on the relative strength of supply and demand reactions, represented by the values of supply and demand elasticities which determine the incidence of tax changes on wages and employment. A second aspect of the dynamic scoring approach is that the heterogeneity in behavioural reactions is factored-in. The theoretical and empirical tax literature has documented the differential effect of tax changes on labour incentives. Low-income individuals in particular face very high marginal tax rates in countries

${ }^{2}$ Barrios et al. (2019) also includes a summary description of the EUROMOD and QUEST models focussing on the features relevant for the dynamic scoring approach. 
with generous welfare systems. A general consensus has emerged suggesting that working tax credits can represent an efficient way to promote labour supply in these circumstances (Immervoll et al. 2007). Such policy may also yield net fiscal gains if the direct negative effect of such tax expenditures on tax revenues is more than compensated by the extra-revenues generated through increased employment (Barrios et al. 2018a). Heterogeneity is therefore of the essence when analysing tax reforms, since tax reforms affect individuals in many different ways which result in different behavioural reactions. Such heterogeneity is also central when considering the question of capital taxation. Recent work in this respect suggests that, given that capital income derives from individuals' differences in saving abilities and skills, capital taxes can be used to complement labour taxes, in particular by allowing to lower them and reduce their distortionary effect (Saez - Stantcheva 2018). Considering the micro-dimension of tax reforms is therefore relevant to account for equity issues and to better capture their impact across the skill distribution and throughout the entire economic system. The following section illustrates how the dynamic scoring approach can be implemented considering the hypothetical case of progressive tax reforms in CEE countries.

\section{ANALYSING THE GROWTH IMPACT OF TAX REFORMS: MOVING FROM FLAT TO PROGRESSIVE TAXES IN CENTRAL AND EASTERN EUROPEAN (CEE) COUNTRIES}

In this section, I illustrate the use of the dynamic scoring approach to analyse the growth effect of hypothetical progressive tax reforms in a set of and CEE countries that currently apply a flat PIT rate. I compare the results of this analysis with the ones obtained using cross-country panel regressions. I focus on the comparison between two approaches: the empirical growth regression analysis and the dynamic scoring approach.

The flat tax reforms implemented in CEE countries represent in many respects good case studies to analyse the impact of taxation on growth. First, they can be considered as fundamental tax reforms, i.e., significant changes in the way the tax system works with likely impact on economic activity and public finances. Fundamental tax reforms can in particular be distinguished from incremental or marginal tax reforms, which are much more common. Such radical changes are better identified in time and should, in principle, lead to observable impact. Furthermore, CEE countries that adopted a flat tax system did so in order to simplify their tax systems and to promote growth and employment through significant reduction in the top tax rates, as well as to fight tax evasion. Both international institutions and the existing literature, at least at the time, suggested that the adoption of flat tax systems was warranted in the context of the transition from centrally planned to market economies (Ivanova et al. 2005). For this reason too, one would expect a possible influence of tax reform on CEE countries' growth performance.

CEE countries have successively adopted single PIT rates since the mid-1990s. Estonia and Lithuania were the first among these countries to adopt such a system in 1994, followed by Latvia in 1997, Romania in 2005, Bulgaria in 2008 and Hungary in 2011. Table 1 provides the values of the single PIT in these countries as of 2017, together with the range of the progressive tax rates in force before the introduction of their flat tax regime. In general, flat tax rates values were set in the vicinity of the minimum tax rates under the previous tax regime, with the 
Table 1. Flat tax systems in Central and Eastern European countries

\begin{tabular}{|l|c|c|c|}
\hline & $\begin{array}{c}\text { Year of introduction } \\
\text { of Flat PIT }\end{array}$ & PIT rate in 2017 & $\begin{array}{c}\text { PIT rate before the introduction } \\
\text { of a flat tax system }\end{array}$ \\
\hline Bulgaria & 2008 & $10 \%$ & $10-24 \%$ \\
\hline Estonia & 1994 & $20 \%$ & $16-35 \%$ \\
\hline Hungary & 2011 & $16 \%$ & $17-32 \%$ \\
\hline Lithuania & 1994 & $15 \%$ & $18-33 \%$ \\
\hline Latvia & 1997 & $23 \%$ & $10-25 \%$ \\
\hline Romania & 2005 & $16 \%$ & $18-40 \%$ \\
\hline Top PIT rate - EU average & - & $45.1 \%$ & - \\
\hline
\end{tabular}

Source: Barrios et al. (2020) and author's calculation.

exception of Latvia. The negative social impact of the introduction of flat tax systems was also to some extent reduced by the adoption of tax allowances and tax credits.

It is arguably difficult to analyse the extent to which flat tax reforms have influenced CEE countries, growth, not least because many other factors should be taken into account. One should consider in particular that in some countries such as Lithuania and Latvia, the adoption of flat tax regimes coincided with deep structural changes characterised by low, and in many cases negative, growth rates. The recent great recession was also exceptional in some countries, such as Estonia and Latvia. However, despite these caveats, a number of interesting features can be identified by considering simple descriptive statistics on GDP growth performance in these countries before and after the introduction of flat tax regimes. Table 2 provides such statistics.

At first glance, it does not seem that average GDP growth rates were higher after the introduction of the flat tax regimes, compared to the average growth performance since 1991, with the exception of Romania. This can be seen by comparing the figures of the first column with those of the last six columns of Table 2. GDP growth was clearly higher after the introduction of the flat tax regime compared to the period before it in Estonia, Latvia and Romania. However, when considering the period excluding the transition period (which is set here after 2000) and excluding also the post-flat tax period (i.e. 10 years after the introduction of the flat tax), we cannot observe any clear differential growth pattern, with the exception of Latvia, although in this case the severity of the financial crisis, rather than the adoption of a flat tax regime, might explain the exceptionally negative growth performance.

On can further investigate the causal link between the introduction of flat tax regimes and the GDP performance considering other factors, which are usually included in empirical growth analyses by means of econometric analysis. Here, I follow the standard specification used in the empirical growth literature. The equation tested is the following:

$$
\Delta . y_{i, t}=\beta_{1} . Y_{i, t-1}+\beta_{2} . X_{i, t}+\nu_{i}+\varepsilon_{i, t}
$$

where the indices $i$ and $t$ stand for the country and time dimensions respectively, $\Delta . y_{i, t}$ represents the annual growth rate in the GDP per capita level, $Y_{i, t-1}$ is the lagged level of GDP per capita, $X_{i, t}$ is a set of control variables, $\varepsilon_{i, t}$ represents the error term of the equation and $\nu_{i}$ is the 
Table 2. Average GDP growth rates and flat tax reforms in Central and Eastern European countries

\begin{tabular}{|c|c|c|c|c|c|c|c|c|c|}
\hline & \multirow{2}{*}{$\begin{array}{l}\text { Average } \\
\text { growth } \\
\text { since } \\
1991\end{array}$} & \multirow{2}{*}{$\begin{array}{l}\text { Average growth } \\
\text { since } 1991 \text { and } \\
\text { before flat tax } \\
\text { system }\end{array}$} & \multirow{2}{*}{$\begin{array}{l}\text { Average growth } \\
\text { after } 2000, \\
\text { excluding post- } \\
\text { flat tax reform } \\
\text { period }\end{array}$} & \multicolumn{6}{|c|}{$\begin{array}{l}\text { Average growth rate after the } \\
\text { introduction of a flat tax system }\end{array}$} \\
\hline & & & & $\mathbf{t}+\mathbf{1}$ & $\mathbf{t}+\mathbf{2}$ & $\mathbf{t}+\mathbf{3}$ & $t+4$ & $\mathbf{t}+\mathbf{5}$ & $t+10$ \\
\hline Bulgaria & $2.0 \%$ & $2.0 \%$ & $5.9 \%$ & $1.2 \%$ & $1.3 \%$ & $1.4 \%$ & $1.1 \%$ & $1.0 \%$ & $1.9 \%$ \\
\hline Estonia & $4.0 \%$ & $-1.6 \%$ & $2.8 \%$ & $1.4 \%$ & $3.7 \%$ & $5.0 \%$ & $4.8 \%$ & \begin{tabular}{|l|}
$3.9 \%$ \\
\end{tabular} & $5.8 \%$ \\
\hline Latvia & $1.4 \%$ & $-8.7 \%$ & $0.9 \%$ & $7.7 \%$ & $6.0 \%$ & $5.9 \%$ & $6.0 \%$ & \begin{tabular}{|l|}
$6.2 \%$ \\
\end{tabular} & $7.9 \%$ \\
\hline Lithuania & $1.7 \%$ & $-14.4 \%$ & $3.2 \%$ & $-3.2 \%$ & $-0.4 \%$ & \begin{tabular}{|l|}
$1.7 \%$ \\
\end{tabular} & $2.9 \%$ & $2.2 \%$ & $4.3 \%$ \\
\hline Hungary & $2.1 \%$ & $2.0 \%$ & $2.3 \%$ & $0.0 \%$ & $0.7 \%$ & \begin{tabular}{|l|}
$1.6 \%$ \\
\end{tabular} & $2.0 \%$ & $2.0 \%$ & $2.3 \%$ \\
\hline Romania & $2.2 \%$ & $1.0 \%$ & $5.2 \%$ & $6.3 \%$ & $6.6 \%$ & $7.3 \%$ & $4.7 \%$ & $4.7 \%$ & $3.2 \%$ \\
\hline
\end{tabular}

Source: Ameco and author's calculations.

Notes: the first column provides average GDP rates since 1991 for all countries excepting for Estonia (since 1994), Bulgaria and Hungary (since 1992). Average growth figures after the introduction of flat tax regimes are calculated for the years up to 2017 and are calculated for all years after such introduction.

country-specific effect. Equations such as (1) have long been used in the empirical growth literature on convergence, see for instance Islam (1995) and Temple (1999). In such a setting, the effect of policy reforms is analysed by including additional control variables in the set $X_{i, t}$. The variables included in $X_{i, t}$ account for the traditional determinant of growth convergence, namely the percentage of population with tertiary education, the degree of trade openness and an indicator measuring the quality of institutions taken from the Fraser database. In addition, we consider a policy variable capturing the influence of the tax regime in place in a given country. We use two alternative policy variables. First, we consider a dummy variable indicating the presence of a flat tax regime using the information reported in Table 1 . This variable is meant to capture the fact that, with a flat tax regime, GDP per capita growth is expected to be higher, by a given constant, in the long-run. Alternatively, we could use information on tax rates. One important motivation for introducing a flat tax system was to boost investment and work effort by lowering the top marginal personal income tax (PIT) rate. Table 1 suggests that CEE countries have managed to do this in a significant way, especially compared to the rest of the EU. The use of the top PIT rate as control variable might thus better capture the effect of a flat tax system, while avoiding the restriction regarding the hypothesis of a constant effect such a system may have on average growth.

The expected sign for the $\beta$ coefficients for all control variables is positive and negative only for the top PIT rate and the lag level of the GDP per capita. The expected value of the $\beta$ coefficient on the lag level of GDP per capita is negative if countries with a lower starting level of GDP per capita catch-up. Equation (1) is estimated for all EU countries during the period 19802017. All observations are averaged over 5-years in order to focus on long-term evolution, as traditionally done in the growth literature. Results of estimating (1) are reported in Table 3. Two different panel estimation techniques are used. The first one relies on the fixed effect estimator 
Table 3. The impact of flat tax reform: econometric results from standard growth equation

\begin{tabular}{|c|c|c|c|c|c|c|c|c|c|c|}
\hline $\begin{array}{l}\text { Flat tax } \\
\text { regime } \\
\text { represented } \\
\text { by: }\end{array}$ & $\begin{array}{c}\text { (1) } \\
\text { Fixed } \\
\text { effects }\end{array}$ & $\begin{array}{c}\text { (2) } \\
\text { Fixed } \\
\text { effects } \\
\text { Dummy } \\
\text { variable }\end{array}$ & $\begin{array}{c}\text { (3) } \\
\text { Fixed } \\
\text { effects } \\
\text { Dummy } \\
\text { variable }\end{array}$ & \begin{tabular}{|c|} 
(4) \\
Fixed \\
effects \\
Top PIT tax \\
rate
\end{tabular} & \begin{tabular}{|c|} 
(5) \\
Fixed \\
effects \\
Top PIT tax \\
rate
\end{tabular} & $\begin{array}{c}\text { (6) } \\
\text { GMM } \\
\text { system }\end{array}$ & $\begin{array}{c}\text { (7) } \\
\text { GMM } \\
\text { system } \\
\text { Dummy } \\
\text { variable }\end{array}$ & $\begin{array}{c}\text { (8) } \\
\text { GMM } \\
\text { system } \\
\text { Dummy } \\
\text { variable }\end{array}$ & $\begin{array}{c}\text { (9) } \\
\text { GMM } \\
\text { system } \\
\text { Top PIT } \\
\text { rate }\end{array}$ & $\begin{array}{c}\begin{array}{c}\text { (10) } \\
\text { GMM } \\
\text { system }\end{array} \\
\text { Top PIT rate }\end{array}$ \\
\hline $\begin{array}{l}\text { Lag GDP per } \\
\text { capita (log) }\end{array}$ & \begin{tabular}{|c|}
$-0.030 * * *$ \\
$(0.006)$
\end{tabular} & $\begin{array}{c}-0.033 * * * \\
(0.006)\end{array}$ & \begin{tabular}{|c|}
$-0.069 * * *$ \\
$(0.013)$
\end{tabular} & $\begin{array}{c}-0.041^{* * *} \\
(0.007)\end{array}$ & \begin{tabular}{|c|}
$-0.067^{* * *}$ \\
$(0.013)$
\end{tabular} & \begin{tabular}{|c|}
$-0.133^{* * *}$ \\
$(0.023)$
\end{tabular} & \begin{tabular}{|c|}
$-0.107 * * *$ \\
$(0.021)$
\end{tabular} & $\begin{array}{l}-0.049 \\
(0.048)\end{array}$ & \begin{tabular}{|c|}
$-0.124 * * *$ \\
$(0.020)$
\end{tabular} & $\begin{array}{l}-0.048 \\
(0.037)\end{array}$ \\
\hline $\begin{array}{l}\text { Flat tax regime } \\
\text { dummy }\end{array}$ & & $\begin{array}{l}0.020 * * \\
(0.009)\end{array}$ & $\begin{array}{c}0.012 \\
(0.009)\end{array}$ & & & & $\begin{array}{l}0.023 * * \\
(0.009)\end{array}$ & $\begin{array}{l}-0.003 \\
(0.013)\end{array}$ & & \\
\hline Top PIT rate & & & & $\begin{array}{c}-0.000^{*} \\
(0.000)\end{array}$ & $\begin{array}{l}-0.000 \\
(0.000)\end{array}$ & & & & \begin{tabular}{|c|}
$-0.001 * * *$ \\
$(0.000)$
\end{tabular} & $\begin{array}{l}-0.001 \\
(0.001)\end{array}$ \\
\hline $\begin{array}{l}\text { Trade } \\
\quad \text { openness }\end{array}$ & & & $\begin{array}{c}0.008 \\
(0.010)\end{array}$ & & $\begin{array}{c}0.007 \\
(0.011)\end{array}$ & & & \begin{tabular}{|c|}
0.041 \\
$(0.026)$
\end{tabular} & & $\begin{array}{c}0.060^{* * *} \\
(0.021)\end{array}$ \\
\hline $\begin{array}{l}\text { Economic } \\
\text { freedom } \\
\text { index }\end{array}$ & & & $\begin{array}{c}0.010^{* * *} \\
(0.003)\end{array}$ & & $\begin{array}{c}0.011^{* * *} \\
(0.003)\end{array}$ & & & $\begin{array}{l}0.029 * * \\
(0.013)\end{array}$ & & $\begin{array}{l}0.018^{*} \\
(0.011)\end{array}$ \\
\hline $\begin{array}{l}\% \text { tertiary } \\
\text { education }\end{array}$ & & & $\begin{array}{l}0.001^{*} \\
(0.001)\end{array}$ & & $\begin{array}{c}0.001 \\
(0.001)\end{array}$ & & & \begin{tabular}{|c|}
0.003 \\
$(0.002)$
\end{tabular} & & $\begin{array}{c}0.002 \\
(0.002)\end{array}$ \\
\hline $\begin{array}{l}\text { Lag GDP per } \\
\text { capita } \\
\text { growth }\end{array}$ & & & & & & $\begin{array}{c}0.369 * * * \\
(0.102)\end{array}$ & $\begin{array}{c}0.133 \\
(0.103)\end{array}$ & $\begin{array}{l}-0.049 \\
(0.048)\end{array}$ & $\begin{array}{c}0.270 * * * \\
(0.100)\end{array}$ & $\begin{array}{c}0.166 \\
(0.201)\end{array}$ \\
\hline Constant & $\begin{array}{c}0.129 * * * \\
(0.020)\end{array}$ & $\begin{array}{c}0.136^{* * * *} \\
(0.020)\end{array}$ & $\begin{array}{c}0.169 * * * \\
(0.031)\end{array}$ & $\begin{array}{c}0.185 * * * \\
(0.033)\end{array}$ & $\begin{array}{c}0.160 * * * \\
(0.042)\end{array}$ & $\begin{array}{c}0.109 * * * \\
(0.017)\end{array}$ & $\begin{array}{c}0.062 * * * \\
(0.017)\end{array}$ & $\begin{array}{c}0.003 \\
(0.058)\end{array}$ & $\begin{array}{c}0.072 * * * \\
(0.014)\end{array}$ & $\begin{array}{c}0.049 \\
(0.053)\end{array}$ \\
\hline Observations & 167 & 167 & 165 & 163 & 161 & 139 & 139 & 107 & 135 & 105 \\
\hline R-squared & 0.171 & 0.199 & 0.251 & 0.211 & 0.256 & & & & & \\
\hline
\end{tabular}

(continued) 
Table 3. Continued

\begin{tabular}{|c|c|c|c|c|c|c|c|c|c|c|}
\hline $\begin{array}{l}\text { Flat tax } \\
\text { regime } \\
\text { represented } \\
\text { by: }\end{array}$ & $\begin{array}{c}\text { (1) } \\
\text { Fixed } \\
\text { effects }\end{array}$ & $\begin{array}{c}\text { (2) } \\
\text { Fixed } \\
\text { effects } \\
\text { Dummy } \\
\text { variable }\end{array}$ & $\begin{array}{c}\text { (3) } \\
\text { Fixed } \\
\text { effects } \\
\text { Dummy } \\
\text { variable }\end{array}$ & $\begin{array}{c}\text { (4) } \\
\text { Fixed } \\
\text { effects } \\
\text { Top PIT tax } \\
\text { rate }\end{array}$ & $\begin{array}{c}\text { (5) } \\
\text { Fixed } \\
\text { effects } \\
\text { Top PIT tax } \\
\text { rate }\end{array}$ & $\begin{array}{c}\text { (6) } \\
\text { GMM } \\
\text { system }\end{array}$ & $\begin{array}{c}\text { (7) } \\
\text { GMM } \\
\text { system } \\
\text { Dummy } \\
\text { variable }\end{array}$ & $\begin{array}{c}\text { (8) } \\
\text { GMM } \\
\text { system } \\
\text { Dummy } \\
\text { variable }\end{array}$ & $\begin{array}{c}\text { (9) } \\
\text { GMM } \\
\text { system } \\
\text { Top PIT } \\
\text { rate }\end{array}$ & $\begin{array}{c}\text { (10) } \\
\text { GMM } \\
\text { system } \\
\text { Top PIT rate }\end{array}$ \\
\hline $\begin{array}{l}\text { Number of } \\
\text { countries }\end{array}$ & 28 & 28 & 28 & 28 & 28 & 28 & 28 & 28 & 28 & 28 \\
\hline$P$-value & 0.000 & 0.000 & 0.000 & $3.15 e-07$ & $1.86 \mathrm{e}-07$ & & & & & \\
\hline Sargan test & & & & & & 39.4 & 53.61 & 41.85 & 45.15 & 47.21 \\
\hline$P$-Value & & & & & & 0.012 & 0.001 & 0.268 & 0.077 & 0.505 \\
\hline
\end{tabular}

Notes: Standard errors in parentheses. $* * * P<0.01, * * P<0.05, * P<0.1$

The dependent variable is the average growth rate of GDP per capita by country for all EU countries during the period 1980-2017. GDP per capita is taken from the AMECO database of the European Commission. Trade openness is the ratio between the sum of total exports and imports over GDP, also from AMEC0. The economic freedom index is taken from the Fraser Institute, and is a summary indicator ranking countries according to five dimensions: size of government, legal structure and security of property rights, access to sound money, freedom to trade internationally, and regulation of credit, labour and business. The education variable is taken from the Barro and Lee database and measures the percentage of population with a tertiary education level completed. 
where $\nu_{i}$ can be controlled for by removing country-specific average values of the variables. The estimation of (1) can suffer from endogeneity bias since the unobserved panel-level effects can be correlated with the lags of the dependent variable. One can use the dynamic panel data system estimator developed by Arellano-Bover/Blundell-Bond, using GMM estimation on first differenced variables in order to account for country-fixed effects (Windmeijer 2005). We first estimate the basic growth equation using the fixed effect estimator, see Column (1) in Table 3. The standard assumption regarding the link between the GDP per capita growth rate and the lag level of GDP per capita is validated by this estimation, suggesting that countries with a low GDP per capita ratios tend to grow faster on average than the rest of the EU. Next, we add a dummy variable taking a value equal to 1 for countries and years during which a flat tax regime was in place. The results reported in Column (2) tend to corroborate the hypothesis according to which, the introduction of a flat tax regime tends to increase growth in the long-run. On average, the growth rate in GDP per capita would be higher by 2 percentage points for countries with a flat tax regime, which is arguably a very high value. The coefficient appears to be significant at the $5 \%$ confidence level. However, this result no longer holds once we control for additional determinants of the GDP per capita growth rate, see Column (3). In this case, the coefficient on the flat tax regime dummy variable is reduced to $1.2 \%$, and is no longer statistically significant. Columns (6)-(8) replicate the same estimations using the GMM system estimator instead. With this method, we control for the possible endogeneity of control variables, in particular in the case of tax policies. ${ }^{3}$ The coefficient of the flat tax regime dummy variable is positive and significant in the simple model incorporating this variable together with the lagged dependent variable and the lagged level of GDP per capita, see Column (7). The coefficient is also statistically significant and with a value comparable to the fixed effect estimator displayed in Column (2). However, here again, the coefficient of the flat tax dummy variable loses its significance once we incorporate the full set of control variables as in the case of the fixed effect estimation. The use of the top PIT tax rate instead of the flat tax dummy reproduces the same pattern, see columns 9 and 10. These results therefore tend to corroborate previous discussion on the lack of robustness of econometric estimations, as well as the higher relevance of non-tax determinants to explain cross-country differences in growth performance.

Generally speaking, the econometric approach to analyse the impact of tax reforms on growth suffers from at least three main limitations, which make their results difficult to use for policy recommendations. The first limitation has been mentioned previously: results stemming from cross-country panel regressions are fraught with methodological issues linked to the endogeneity of variables used, the potential existence of unobservable determinants of growth, possibly correlated with the policy reform under analysis, and the misspecification of the equation tested. The second limitation is that policy reform can be expected to have only marginal effects on growth performance. This is evidenced by the growth literature, which focuses on many other, arguably more important, factors, such as human capital, demographic, trade openness and technological progress. This is reflected to some extent by the results reported in Table 3. A third important reason, possibly the most important one for policy, is the difficulty to draw counter-factual scenarios using the econometric approach. In this case, the

${ }^{3} \mathrm{Up}$ to three lags of the explanatory variables are used as instruments. The Sargan test tends to corroborate the validity of the instrument sets chosen for the complete models (8) and (10). 
relevant question is: what if the CEE countries had adopted or kept progressive tax regime? This question can hardly be answered reliably using econometric estimations. Rodrik (2012) explains why this is the case in a very convincing way. His reasoning runs as follows. Government reforms can be motivated by two aims: one genuine aim to achieve a specific objective such as boosting growth or employment and other, less genuine, political motives e.g., to win elections or to benefit specific interest groups. Accordingly, reforms would not be random, but rather motivated by specific objectives driven by the very circumstances that these aim to address, which can be to boost growth and/or to win general elections. The key issue is therefore to identify the effects of policy reforms given that these are not exogenous, and that the causality link between tax reform and growth might be blurred by the objective motivating the policy reform. The end result is that the cross-country variation in policy reforms, which the analyst may be tempted to classify in terms of good and bad policies, is unlikely to be random and more likely to be driven by the problem the government is aiming to address. In our case, this would mean that even if flat tax reforms were motivated by a genuine aim of boosting growth, one could possibly find a negative coefficient on the dummy variable capturing the existence of such reforms if governments were not able to completely achieve their objective or, if their aim was not exclusively to boost growth.

One way to identify the impact of flat tax systems would be to compare the GDP performance under such a regime to the one observed under a progressive tax regime. With such an approach, the issue of identification and endogeneity would be absent. Both the econometric and the QUEST models can be used to conduct such counter-factual analysis. Results using the QUEST model are taken from Barrios et al. (2019) using the dynamic scoring approach described in Section 2. ${ }^{4}$ We then compare these results with the projections based on the fixed effects model and the GMM-system estimations.

The simulations using the dynamic scoring approach have been conducted as follows. The same progressive tax system is implemented in each country with the first rate being simply the current flat tax rate reduced by 5 percentage points, the current flat tax rate would represent the middle rate and the top rate is equal to the middle rate increased by 7 percentage points. The first income threshold is also set to $33 \%$ of the average net taxable income (being defined as the gross taxable income minus applicable allowances). The progressive tax schedule was also combined with the introduction of a refundable in-work tax credit in order to neutralize the budgetary effects of the introduction of the progressive tax system and to address potential disincentive effects on labour supply. Budget neutrality was ensured through the introduction of compensating measures, which represents another distinctive advantage compared to the econometric approach. Two alternatives scenarios were considered: one in which the compensating measures ensured budget balance in level (Scenario 1), and the other where the budget balance in terms of percentage of GDP was kept constant in order to neutralize possible changes in GDP variation created by the reform (Scenario 2). The simulations using the econometric models are more straightforward. When using the model estimated in Column (3) of Table 3, we just need to assume that the flat tax regime dummy variable takes values equal to

\footnotetext{
${ }^{4}$ Note that in the EUROMOD-QUEST approach most shocks do not influence population relative to the baseline assumption, therefore, GDP and GDP/capita changes are the same relative to the baseline, and one can compare the projections based on this approach with the one based on the econometric estimation using GDP per capita as dependent variable.
} 
Table 4. Medium and long-run impact of progressive tax reforms in Central and Eastern European countries: GDP per capita growth rate differential vs. baseline growth (percentage points)

\begin{tabular}{|c|c|c|c|c|}
\hline Time & $\begin{array}{l}\text { QUEST- simulations } \\
\text { (scenario 1) }\end{array}$ & $\begin{array}{l}\text { QUEST- simulations } \\
\text { (scenario 2) }\end{array}$ & $\begin{array}{l}\text { Growth regressions } \\
\text { (Dummy variable) }\end{array}$ & $\begin{array}{l}\text { Growth regressions } \\
\text { (Top PIT rate) }\end{array}$ \\
\hline \multicolumn{5}{|l|}{ Bulgaria } \\
\hline$t+1$ & 0.001 & 0.004 & -1.200 & -0.095 \\
\hline$t+2$ & 0.007 & 0.014 & -1.139 & -0.085 \\
\hline$t+3$ & 0.013 & 0.023 & -1.136 & -0.091 \\
\hline$t+4$ & 0.016 & 0.028 & -1.210 & -0.090 \\
\hline$t+5$ & 0.017 & 0.030 & -1.260 & -0.095 \\
\hline Long-run & 0.020 & 0.034 & -1.176 & -0.089 \\
\hline \multicolumn{5}{|l|}{ Estonia } \\
\hline$t+1$ & 0.002 & 0.001 & -1.928 & -0.101 \\
\hline$t+2$ & 0.005 & 0.005 & -1.887 & -0.095 \\
\hline$t+3$ & 0.014 & 0.012 & -2.059 & -0.106 \\
\hline$t+4$ & 0.022 & 0.018 & -1.989 & -0.101 \\
\hline$t+5$ & 0.026 & 0.022 & -1.978 & -0.098 \\
\hline Long-run & 0.030 & 0.025 & -2.013 & -0.096 \\
\hline \multicolumn{5}{|l|}{ Hungary } \\
\hline$t+1$ & 0.001 & -0.003 & -0.510 & -0.112 \\
\hline$t+2$ & 0.018 & 0.019 & -0.588 & -0.113 \\
\hline$t+3$ & 0.032 & 0.040 & -0.539 & -0.113 \\
\hline$t+4$ & 0.038 & 0.049 & -0.603 & -0.114 \\
\hline$t+5$ & 0.039 & 0.050 & -0.538 & -0.107 \\
\hline Long-run & 0.029 & 0.033 & -0.495 & -0.107 \\
\hline \multicolumn{5}{|l|}{ Latvia } \\
\hline$t+1$ & 0.015 & 0.006 & -2.047 & 0.015 \\
\hline$t+2$ & 0.001 & 0.004 & -2.077 & 0.012 \\
\hline$t+3$ & 0.015 & 0.019 & -1.997 & 0.017 \\
\hline$t+4$ & 0.031 & 0.033 & -2.027 & 0.018 \\
\hline$t+5$ & 0.044 & 0.044 & -2.149 & 0.012 \\
\hline Long-run & 0.066 & 0.068 & -2.150 & 0.015 \\
\hline
\end{tabular}

(continued) 
Table 4. Continued

\begin{tabular}{|l|c|c|c|c|}
\hline Time & $\begin{array}{c}\text { QUEST- simulations } \\
\text { (scenario 1) }\end{array}$ & $\begin{array}{c}\text { QUEST- simulations } \\
\text { (scenario 2) }\end{array}$ & $\begin{array}{c}\text { Growth regressions } \\
\text { (Dummy variable) }\end{array}$ & $\begin{array}{c}\text { Growth regressions } \\
\text { (Top PIT rate) }\end{array}$ \\
\hline \multicolumn{5}{|l|}{ Lithuania } \\
\hline $\mathrm{t}+1$ & 0.006 & 0.000 & -1.952 & -0.122 \\
\hline $\mathrm{t}+2$ & 0.009 & 0.002 & -1.904 & -0.121 \\
\hline $\mathrm{t}+3$ & 0.023 & 0.005 & -2.046 & -0.124 \\
\hline $\mathrm{t}+4$ & 0.034 & 0.006 & -2.080 & -0.120 \\
\hline $\mathrm{t}+5$ & 0.039 & 0.007 & -2.045 & -0.123 \\
\hline Long-run & 0.041 & 0.008 & -2.063 & -0.127 \\
\hline Romania & & & & -0.171 \\
\hline $\mathrm{t}+1$ & 0.006 & -0.002 & -1.131 & -0.173 \\
\hline $\mathrm{t}+2$ & 0.009 & 0.002 & -1.291 & -0.174 \\
\hline $\mathrm{t}+3$ & 0.023 & 0.007 & -1.363 & -0.175 \\
\hline $\mathrm{t}+4$ & 0.034 & 0.010 & -1.409 & -0.172 \\
\hline $\mathrm{t}+5$ & 0.039 & 0.012 & -1.331 & -0.171 \\
\hline Long-run & 0.041 & 0.010 & -1.350 & \\
\hline
\end{tabular}

Note: QUEST projections are based on Barrios et al. (2020). Growth regressions projections are based on Eq. (1) and estimations in Table 3 Column (3) for the growth regression with a dummy variable in order to capture the shift to a flat tax policy regime, and Column (9) for the growth regression including the top PIT rate instead.

zero after the last year of observation. When using instead the top PIT rate, we assume that the value of this variable returns to its country-specific level before the flat tax reform. The calibration year for the dynamic scoring approach is 2017, which is also the last year of data used in the econometric estimations. The impact of the progressive tax reform on GDP per capita growth rates are measured in terms of the difference of the predicted GDP per capita growth rate compared to its baseline value. ${ }^{5}$ We need to set hypothetical values for the other control variables too in the econometric model. For the lag level of the GDP per capita, we use the value of the IMF's long-run projections from the October 2019 edition of the World Economic Outlook). For the other control variables, we simply assumed that they remained fixed at their value for the year 2017. The results of these projections are reported in Table 4.

The results of the EUROMOD-QUEST simulation reported in Table 4 suggest that the impact of moving from a flat to a progressive tax system would be negligible. Both scenarios considered yield very similar results. In most cases, the impact of such reforms would lead to very small deviation from the baseline growth rate, between 0 percentage points and 0.07 percentage points, and would be slightly positive. The long-run impact (i.e. at $t+10$ ) would be as

${ }^{5}$ This is because the QUEST and econometric models each have specific baselines. 
low as in the medium-run (i.e. up to $t+5$ ). Interestingly therefore, these results suggest that the impact of progressive tax reforms on GDP per capita growth would be contained and slightly positive. The conclusions drawn from the econometric estimations are rather different, especially when considering the model using the dummy variable. In this case, the projections show that the introduction of progressive tax systems would lead to substantial reduction in GDP per capita, varying from -0.5 percentage points to -2.15 percentage points compared to the baseline growth rate. These results should not be too surprising given the parsimony of the econometric model. Such projections are also conducted under the assumption that the other determinants of growth embodied in $X_{i, t}$ remain constant while the only variables to experience a change are the lag level of GDP per capita (which is set in line with the IMF long-run projections) and the policy dummy variable. More importantly, the switch from a flat to a progressive tax regime is simply captured by a change in the dummy variable assuming a constant effect of the flat tax system on average growth. Such a change can also capture many other things, which might, or might not, be correlated with the change in the tax policy regime. The projections using the top PIT rate suggests that the reduction in GDP growth per capita is likely to be much lower, however. On average, the reduction in average growth is predicted to be lower by 0.12 percentage points in the medium and long-run. In the case of Latvia, the average growth rate is found to be larger by 0.15 on average. However, generally speaking, the magnitude of the effect of progressive tax reforms is expected to be much bigger when using the econometric model instead of the dynamic scoring approach.

The projections yielded by the econometric approach face important limitations compared to the dynamic scoring approach. In particular, the presence of (or change in) a given policy regime cannot capture possible feedback effects that a progressive tax reform may have on the economy. For instance, low-income workers would be expected to benefit from higher incomes and could increase their consumption, and possibly their participation in the labour market, if the progressive tax reform was accompanied by an in-work tax credit scheme as advocated by Diamond and Saez (2011). These complementary reforms might, in turn, counter the adverse disincentive effects of higher taxes on high-income individuals and private investment, for instance. The dynamic scoring approach captures these effects, showing that the fall in GDP growth rates are unlikely to be as dramatic as suggested by the growth regression model. One must note that the dynamic scoring approach might also face limitations, for instance due to the hypothesis of unchanged behavioural parameters used to calibrate these models. This analysis shows that the advantage of this method lies in the identification of the channels through which policy reforms operate, and the possibility to draw counter-factual scenarios. One should note, however, that the simulations using the econometric estimations are not fully comparable with the ones using the QUEST model, given that, with the latter, we combine the switch to a progressive tax regime with the introduction of a working tax credit. However, the very large discrepancy in the medium and long-run projections of GDP per capita growth are unlikely to be fully explained by this difference, especially since the marginal effect of the econometric estimate is rather high and sensitive to three factors: the estimation method used, the inclusion of additional control variables, and to the variable used to represent the change in the tax policy regime. Future work could investigate alternative policy simulations using the dynamic scoring approach that could yield results based on closer policy assumptions. 


\section{SUMMARY AND CONCLUSION}

The impact of tax reforms on growth represents a key concern for policy makers. The economic literature provides a wide range of arguments showing that this impact depends on the tax category considered and the circumstances under which such reforms are conducted. Yet, the existing empirical literature based on cross-country econometric estimations provides inconclusive results on the relationship between taxation and growth, notably due to identification and endogeneity issues, and to the difficulty to account for the circumstances under which tax reforms are conducted. Considering the specific case of flat tax regimes in CEE countries, I argue that growth regressions are, at best, unhelpful in saying something about the growth impact of the introduction of progressive tax reforms in these countries. At worst, they could lead to wrong conclusions and biased policy recommendations.

Recent developments in the analysis of tax reforms combining microsimulation and macro models prove more useful in this respect, especially when it comes to drawing policy recommendations. This paper illustrates how microsimulation and macro-models can be combined in order to analyse the impact of tax reforms on growth and yield more reliable and, possibly more useful results for policy making. The dynamic scoring approach accounts for the heterogeneity in the behaviour of economic agents, which must be considered given that tax reforms are unlikely to affect individuals equally across the income/skill distribution. I show in particular that, under a hypothetical reversal to a progressive tax regime in CEE countries with a flat tax system, the results obtained from the dynamic scoring approach would prove more realistic than the ones derived from standard cross-country econometric estimations. I find that the estimated impact of moving from flat to progressive income taxes would be rather small but positive when using the dynamic scoring method, while the less-reliable traditional growth regressions would suggest adverse growth effects.

Importantly, the use of dynamic scoring allows counter-factual analyses and can be used to identify the mechanisms through which tax reforms might impact on growth. This is a clear advantage compared to econometric analyses based cross-country regressions. The main drawback of this approach, however, is its reliance on calibrated parameters, most notably labour supply elasticities which are estimated econometrically. The behavioural and second-round effects estimated this way rely on the assumption that individuals' reactions will not be affected by the policy reforms. This is debatable, especially if governments' reforms aim to boost growth through higher employment, which may alter individuals' expectation on future wages. However, such an assumption is not necessarily wrong given that agents may take time to adapt their behaviour to policy reforms due to the uncertainty surrounding their impact, or simply because of institutional features and related frictions in the labour market. This would be the case for instance when considering barriers to hiring/firing workers or due to the limited flexibility to adapt working time.

\section{ACKNOWLEDGEMENTS}

I wish to thank the participants of the 2nd Annual Public Finance Conference organised by the Hungarian Treasury, Daniel Daco, Zsolt Darvas, Wouter van der Wielen and two anonymous referees for useful comments. The views expressed in this paper do not necessarily reflect those of the European Commission. Any error should be attributed to the author only. 


\section{REFERENCES}

Aghion, P. - Akcigit, U. - Fernández-Villaverde, J. (2013): Optimal Capital Versus Labor Taxation with Innovation-led Growth. NBER Working Paper 19086.

Akcigit, U. - Grigsby, J. R. - Nicholas, T. - Stantcheva, S. (2019): Taxation and Innovation in the 20th Century. NBER Working Paper 24982.

Akgun, O. - Cournède, B. - Fournier, J. (2017): The Effects of the Tax Mix on Inequality and Growth. OECD Economics Department Working Papers No. 1447, Paris: OECD Publishing.

Arnold, J. - Brys, B.- Heady, C. - Johansson, A. - Schwellnus, C. - Vartia, L. (2011): Tax Policy for Economic Recovery And Growth. Economic Journal 121(550): F59-F80.

Atkinson, A. B. - Stiglitz, J. E. (1976): The Design of Tax Structure: Direct Versus Indirect Taxation. Journal of Public Economics 6(1-2): 55-75.

Auerbach, A. M. - Devereux, P. - Simpson, H. (2010): Taxing Corporate Income. In: Dimensions of Tax Design. The Mirrlees Review. London: Oxford University Press, Ch. 9.

Auerbach, A. J. -Hines, J. R. Jr. (2002): Taxation and Economic Efficiency. In: Feldstein, M. - Auerbach, A. J. (eds.): Handbook of Public Economics, Vol. 3. Amsterdam: Elsevier, pp. 1347-1421.

Baiardi, D. - Profeta, P. - Puglisi, R. - Scabrosetti, S. (2019): Tax Policy and Economic Growth: Does It Really Matter? International Tax and Public Finance 26: 282-316.

Bargain, O. - Orsini, K. - Peichl, A. (2014): Comparing Labor Supply Elasticities in Europe and the United States: New Results. Journal of Human Resources 49(3): 723-838.

Barrios, S. - Fatica, S. - Martinez Lopez, D. - Mourre, G. (2018a): The Fiscal Effects of Work-related Tax Expenditures in Europe. Public Finance Review 46(5): 793-820.

Barrios, S. - Nicodème, G. - Sanchez Fuentes, A. G. (2018b): Multi-Factor Effective Corporate Taxation, Firms' Mark-Ups and Tax Incidence: Evidence from OECD Countries. Fiscal Studies 39(3): 417-453.

Barrios, S. - Dolls, M. - Maftei, A. - Peichl, A. - Riscado, S. - Varga, J. - Wittneben, C. (2019): Dynamic Scoring of Tax Reforms in the European Union. Journal of Policy Analysis and Management 38(1): 239-262.

Barrios, S. - Maftei, A. - Ivaskaite, V. - Narazani, E. (2020): Progressive Tax Reforms in Flat Tax Countries. Eastern European Economics 58(2): 83-107.

Bastani, S. - Waldenström, D. (2018): How Should Capital be Taxed? Theory and Evidence from Sweden. WID Working Paper 2018/9.

Bingley, P. - Lanot, G. (2002): The Incidence of Income Tax on Wages and Labour Supply. Journal of Public Economics 83: 173-194.

Blanchard, O. - Perotti, R. (2002): An Empirical Characterization of the Dynamic Effects of Changes in Government Spending and Taxes on Output. Quarterly Journal of Economics 117(4): 1329-1368.

Blundell, R. (2012): Tax Policy Reform: The Role of Empirical Evidence. Journal of the European Economic Association 10(1): 43-77.

Chamley, C. (1986): Optimal Taxation of Capital Income in General Equilibrium with Infinite Lives. Econometrica: Journal of the Econometric Society 54(3): 607-622.

Dabla-Norris, M. E. - Lima, F. (2018): Macroeconomic Effects of Tax Rate and Base Changes: Evidence from Fiscal Consolidations. Washington DC: International Monetary Fund.

Diamond, P. - Saez, E. (2011): The Case for a Progressive Tax: From Basic Research to Policy Recommendations. Journal of Economic Perspectives 25(4): 165-190.

Easterly, W. - Rebelo, S. (1993): Fiscal Policy and Economic Growth. Journal of Monetary Economics 32(3): 417-458. 
Feldstein, M. (2006): The Effect of Taxes on Efficiency and Growth. NBER working paper 12201, National Bureau of Economic Research.

Fuest, C. - Peichl, A. - Siegloch, S. (2018): Do Higher Corporate Taxes Reduce Wages? Micro Evidence from Germany. American Economic Review 108(2): 393-418.

Fullerton, D. - Metcalf, G. E. (2002): Tax Incidence. Handbook of public economics 4: 1787-1872.

Gerber, C. - Klemm, A. - Liu, L. - Mylonas, V. (2018): Personal Income Tax Progressivity: Trends and Implications. IMF Working Paper 18/246.

Gravelle, J. (2014): Dynamic Scoring for Tax Legislation: A Review of Models. Washington, DC: Congressional Research Service.

Immervoll, H. - Kleven, H. J. - Kreiner, C. T. - Saez, E. (2007): Welfare Reform in European Countries: A Microsimulation Analysis. Economic Journal 117(516): 1-44.

Islam, N. (1995): Growth Empirics: A Panel Data Approach. The Quarterly Journal of Economics 110(4): $1127-1170$.

Ivanova, A. - Keen, M. - Klemm, A. (2005): The Russian Flat Tax Reform. Economic Policy 20(43): 397-444. Judd, K. L. (1985): Redistributive Taxation in a Simple Perfect Foresight Model. Journal of Public Economics 28(1): 59-83.

Piketty, T. - Saez, E. (2012): A Theory of Optimal Capital Taxation. NBER Working Paper 17989.

Ratto, M. - Roeger, W. - In't Veld, J. (2009): QUEST III: An Estimated Open-economy DSGE Model of the Euro Area with Fiscal and Monetary Policy. Economic Modelling 26: 222-233.

Rodrik, D. (2012): Why We Learn Nothing from Regressing Economic Growth on Policies. Seoul Journal of Economic 25(2): 137-151.

Romer, C. D. - Romer, D. H. (2010): The Macroeconomic Effects of Tax Changes: Estimates Based on a New Measure of Fiscal Shocks. American Economic Review 100(3): 763-801.

Saez, E. (2001): Using Elasticities to Derive Optimal Income Tax Rates. Review of Economic Studies 68: 205-229.

Saez, E. - Stantcheva, S. (2018): A Simpler Theory of Optimal Capital Taxation. Journal of Public Economics 162: $120-142$.

Stokey, N. - Rebelo, S. (1995): Growth Effects of Flat-Tax Rates. Journal of Political Economy 103: 519-550.

Sutherland, H. - Figari, F. (2013): EUROMOD: The European Union Tax-benefit Microsimulation Model. EUROMOD Working Paper EM8/13.

Suárez Serrato, J. C. - Zidar, O. (2016): Who Benefits from State Corporate Tax Cuts? A Local Labor Markets Approach with Heterogeneous Firms. American Economic Review 106(9): 2582-2624.

Temple, J. (1999): The New Growth Evidence. Journal of Economic Literature 37(1): 112-156.

Van der Wielen, W. (2020): The Macroeconomic Effects of Tax Changes: Evidence Using Real-time Data for the European Union. Economic Modelling 90: 302-321.

Windmeijer, F. (2005): A Finite Sample Correction for the Variance of Linear Efficient Two-step GMM Estimators. Journal of Econometrics 126: 25-51.

Xing, J. (2012): Tax Structure and Growth: How Robust is the Empirical Evidence? Economic Letters 117: $379-382$.

Yagan, D. (2015): Capital Tax Reform and the Real Economy: The Effects of the 2003 Dividend Tax Cut. American Economic Review 105(12): 3531-3563.

Open Access. This is an open-access article distributed under the terms of the Creative Commons Attribution-NonCommercial 4.0 International License (https://creativecommons.org/licenses/by-nc/4.0/), which permits unrestricted use, distribution, and reproduction in any medium for non-commercial purposes, provided the original author and source are credited, a link to the CC License is provided, and changes - if any - are indicated. 